\title{
Considerações sobre o assédio moral como fator contribuinte para os episódios depressivos no trabalho: a violência velada e o adoecimento mental do trabalhador
}

\section{Considerations about moral harassment as a contributory factor to depressive episodes at work: veiled violence and mental illness of workers}

\author{
Mário Lázaro Camargo ${ }^{1}$, Natália de Sousa Almeida², Edward Goulart Júnior ${ }^{3}$
}

\section{Resumo}

O trabalho é um importante elemento constituinte da identidade e subjetividade do ser humano, ao passo que também pode participar dos processos de construção do sofrimento físico ou psíquico decorrentes de demandas que vão além do que o indivíduo pode desempenhar em se tratando de suas potencialidades e limitações, sobretudo se ocorrem num ambiente com pouca de qualidade de vida no trabalho. O presente estudo, realizado mediante levantamento temático na literatura nacional, objetivou discutir a relação do assédio moral praticado nas organizações com eventuais prejuízos à saúde mental do trabalhador, especificamente o episódio depressivo. Com base nos principais indexadores científicos (Scielo, BVS-Psi, PepsiCo e Google Scholar) e a partir dos descritores "assédio moral and depressão", com delimitação cronológica até julho de 2018, verificamos uma significativa quantidade de textos acerca do tema assédio moral, porém com pouca quantidade de textos correlacionando o assédio moral e os episódios depressivos no trabalho. Nossas considerações finais, contudo, apontam para a íntima relação entre assédio moral e a vulnerabilidade psíquica no trabalhador, e, por isso, propomos algumas ações estratégicas para a atuação da área de Gestão de Pessoas nas organizações, visando a prevenção e combate ao assédio moral.

Palavras-chave: Assédio moral. Episódios depressivos. Saúde do trabalhador. Gestão de pessoas.

\begin{abstract}
Work is an important constituent element of the identity and subjectivity of the human being, whereas it can also participate in the processes of construction of physical or psychic suffering arise from demands that go beyond what an individual can perform in relation to its potentialities and limitations, especially if they occur in an environment with low quality of life at work. The present study, performed through a theme survey of the national literature, aimed to discuss the relationship of the moral harassment practiced in organizations with possible damages to the worker's mental health, specifically the depressive episode. Based on the main scientific indexers (Scielo, BVS-Psi, PepsiCo and Google Scholar) and
\end{abstract}

1 Doutor em Psicologia pela USP-FFCLRP - Universidade de São Paulo, Faculdade de Filosofia, Ciências e Letras de Ribeirão Preto. Professor Assistente na Unesp - Universidade Estadual Paulista Júlio de Mesquita Filho, Faculdade de Ciências. E-mail: mario.camargo@unesp.br

2 Graduada em Psicologia pela Universidade Estadual Paulista Júlio de Mesquita Filho -Unesp. Faculdade de Ciências, Campus de Bauru.

3 Doutor em Psicologia pela Pontifícia Universidade Católica de Campinas, PUC Campinas. Professor Assistente Doutor da Universidade Estadual Paulista Júlio de Mesquita Filho. 
through the "moral harassment and depression" descriptors, with a chronologial delimitation to July 2018, we verified a significant amount of texts about moral harassment, as well as a lack of texts which correlate moral harassment and depressive episodes at work. Our final considerations point to the intimate relationship between moral harassment and psychic vulnerability in workers and, therefore, we propose some strategic actions for the performance of the area of People Management in organizations, aiming at preventing and combating the moral harassment.

Keywords: Moral Harassment. Depressive episodes. Worker's health. People management.

\section{Introdução}

O trabalho contribui significativamente para a configuração da identidade humana, de modo que compreender o seu significado e o grau de afetividade do indivíduo sobre as atividades laborais é de suma importância para o entendimento da relação homem e trabalho, uma vez que, na contemporaneidade, a maior parte do tempo é dispensada a estas atividades. Contudo, o trabalho também pode ser fonte de malestar e sofrimento, sobretudo quando o trabalhador não se sente valorizado, enfrenta um ambiente hostil e inseguro, e quando suas expectativas estão dissonantes com as contrapartidas oferecidas pelo empregador (CARDOSO; FEIJÓ; CAMARGO, 2018; CAMARGO, 2017; FLORES et al., 2016; CUNHA et al., 2015; LIMONGI-FRANÇA, 2008; DEJOURS; ABDOUCHELI; JAYET, 2007; DEJOURS, 1992; FERNANDES, 1996).

As mudanças no mundo do trabalho vêm ocorrendo de modo intenso e rápido. $\mathrm{A}$ antes previsível e estável condição do mercado, deu lugar a incertezas e oscilações decorrentes da economia e das novas políticas de organizar a sociedade (BERNAL, 2010). Fusões, terceirizações e privatizações tornam-se frequentes, reorganizando as relações de trabalho, aumentando a demanda de exigências ao trabalhador e diminuindo direitos conquistados no passado. Outra questão não menos relevante é a chegada da "era digital" nos contextos de trabalho, que está sendo denominada como a $4^{\text {a }}$ revolução industrial que, segundo Magaldi e Salibi Neto (2018, p. 44), o grande impacto dessa revolução é "o de transformar o modo como os indivíduos vivem, trabalham e se relacionam". Diante desse cenário que se apresenta, considerando a conjuntura política, econômica e social, o contexto organizacional de trabalho, tanto privado quanto público, do mesmo modo, sofre influências e se modifica, podendo, inclusive, se tornar um ambiente no qual hostilidade, exigências acima do que o indivíduo é capaz de corresponder e humilhações podem estar presentes, abrindo espaço para modos agressivos de gerir pessoas, os quais vulnerabilizam a condição de saúde do trabalhador e, consequentemente, potencializam o risco de adoecimento mental.

Muitos ambientes organizacionais, considerando suas políticas e práticas continuam a serem geridos com o mesmo "pensamento" do início das primeiras teorias administrativas (SPECTOR, 2012), voltadas quase que exclusivamente para aumentar a produtividade e lucratividade a qualquer custo, o que leva o indivíduo a trabalhar, frequentemente, muito próximo de seu limite, sobretudo em nível emocional, considerando as pressões e cobranças. Assim, evidencia-se a fragilidade do trabalhador perante esta conjuntura, uma vez que o mesmo está sujeito a um sistema de gestão no qual metas e resultados estipulados são muitas vezes superdimensionados pelos gestores organizacionais (GOULART; GOULART JÚNIOR, 2017). O profissional multitarefas - fenômeno resultante das políticas de redução de custos com pessoal por parte das organizações de trabalho - é valorizado neste cenário, posto que as tarefas, antes desempenhadas por duas ou mais pessoas, agora passam a ser realizadas somente por uma, valendose deste trabalhador "faz tudo", que, por sua vez e para garantir sua empregabilidade e estabilidade, exibe comportamentos adaptativos ao contexto de 
exigências cada vez mais altas, além de aderir às demandas e clima de competitividade por metas ou desempenhos (performace individual) crescentes.

Este contexto de trabalho é propício à prática de atitudes marcadas por formas de violência para com o trabalhador - e vale pontuar: o assédio moral é apenas uma dessas formas - sobretudo quando as lideranças são desqualificadas em termos de formação ou com tendências ao emprego de violência nas relações interpessoais.

Outro fator importante de se considerar é que as organizações, de um modo geral, retiram cada vez mais recursos financeiros dos projetos e áreas que poderiam impactar positivamente na construção de ambientes mais significativamente marcados pela qualidade de vida no trabalho, para destinarem estes mesmos recursos às formas de ampliação de produtividade e lucratividade, a exemplo do que se assiste em termos dos investimentos em tecnologia, marketing e terceirizações. Este fenômeno, fortemente influenciado pelo cenário econômico que põe em risco a existência das organizações, em especial as de capital privado, vulnerabiliza as relações de trabalho e faz com que os chamados fatores psicossociais de risco se apresentem de forma mais perigosa, ou seja, fragilizando a saúde física e mental dos trabalhadores (CARDOSO; FEIJÓ; CAMARGO, 2018; CAMARGO, 2017; BERNAL, 2010).

Segundo Costa e Santos (2013), os fatores psicossociais de risco no trabalho podem ser assim nominados: fator intensidade e tempo de trabalho: relação que se estabelece entre a quantidade de energia dispensada pelo trabalhador para fins de execução de suas atividades e a quantidade de tempo de duração de seus esforços - não desconsiderando que aqueles trabalhadores que dispensam menor período de tempo no trabalho também poderão estar sujeitos a riscos no comprometimento a sua saúde; fator exigências emocionais: as atividades laborais podem exigir do trabalhador, além do esforço físico, um gasto importante de energia psíquica, pois o trabalho mobiliza afetos no sujeito que trabalha e que, para tanto, se relaciona com um contexto de complexidades em se tratando das relações interpessoais - incluindo-se, portanto, os conflitos relacionais e a possibilidade de presença do assédio moral - procedimentos técnicos, adaptação a regras e normas, relação com autoridade, comunicações em diferentes níveis e por variados meios, etc. Portanto, uma carga emocional mais ou menos intensa sempre está presente na relação que se estabelece entre o ser humano e seu trabalho (CARDOSO; FEIJÓ; CAMARGO, 2018; GONDIM; SIQUEIRA, 2014); fator falta ou insuficiência de autonomia: a possibilidade, por parte do trabalhador, de exercitar maior ou menor autonomia na relação com o trabalho e no espaço organizacional se configura como um elemento importante no processo de construção da motivação, do vínculo, do comprometimento e da identificação com o contexto. A falta ou insuficiência de autonomia promove uma relação meramente instrumental com o trabalho, um fazer desprovido ou empobrecido de sentido e significado, com o qual o trabalhador não se identifica e por meio do qual não se reconhece como autor (KUBO; GOUVÊA, 2012; BENDASSOLLI; BORGES-ANDRADE, 2011; BENDASSOLLI, 2009; MORIN, 2001) fator má qualidade das relações sociais: as relações sociais de qualidade são fundamentais para o desenvolvimento de um sentido de pertencimento ao contexto de trabalho. São as relações sociais que permitem o sujeito sentir-se acolhido ou não, importante ou não, parte integrante da dinâmica organizacional e corresponsável com seus resultados. Relações sociais empobrecidas ou marcadas pela presença da violência e hostilidade (assédio moral, por exemplo) desfavorecem o alcance qualitativo da experiência da realização pessoal e profissional no trabalho, afetam o campo subjetivo do trabalhador, tornando-o vulnerável e susceptível à vivência de mais sofrimento do que de prazer; fator conflitos de valores: os contextos de trabalho são comumente marcados por conflitos de valores, em especial aqueles relativos à cultura organizacional, ou seja, 
seu sistema normativo e de crenças, e aqueles trazidos pelo trabalhador (MACÊDO et al., 2005). Quando as exigências e crenças organizacionais conflitam com os valores individuais, ocorre o comprometimento do sentido positivo que o trabalhador atribui ao seu trabalho; fator insegurança na situação de trabalho e emprego: a percepção de ausência de reciprocidade, por parte do trabalhador, entre sua dedicação ao trabalho, produtividade, pontualidade, assiduidade, e a dedicação, por parte da organização, em manter a estabilidade do emprego dos trabalhadores, ou ainda a justa e contratada recompensa pelo trabalho, representa um fator psicossocial de risco que vulnerabiliza o trabalhador, fazendo-o sentir como perigo a proximidade da situação de desemprego, além de representar um possível risco de quebra do contrato psicológico (CHAMBEL, 2015) estabelecido entre trabalhador-organização e percepção de frágil condição de justiça organizacional (BEUREN; AMARO; SILVA, 2015); fator suporte organizacional: a percepção do suporte organizacional, entendido pelo trabalhador como o conjunto de estratégias das quais a organização lança mão para cuidar, proteger e promover seu bem-estar no trabalho (CARDOSO; FEIJÓ; CAMARGO, 2018; SIQUEIRA; GOMIDE JÚNIOR, 2008), representa um importante fator psicossocial, posto que, se observado, gera nos trabalhadores: menos faltas ao trabalho (absenteísmo), menor intenção de sair da empresa (rotatividade), maior desempenho, maior satisfação, maior comprometimento organizacional e com a equipe, maior percepção de bem-estar e melhor aprendizagem (SIQUEIRA; GOMIDE JÚNIOR, 2014).

Pode-se inferir que contextos organizacionais que desconsideram os fatores psicossociais, negligenciam a saúde e a qualidade de vida no trabalho e constituem-se, portanto, em contextos mais susceptíveis a abusos e formas de violência, favorecendo assim a presença do assédio moral considerando que, neles, as relações de trabalho são mais fragilizadas e vulnerabilizadas, impactando negativamente nas relações e interações interpessoais que são estabelecidas. Nesse sentido, convém ressaltar que o assédio moral presentificado no contex to organizacional e nas relações sociais que ali se dão, tanto verticais quanto horizontais, atua como elemento significativamente potencializador dos processos de adoecimento psíquico dos trabalhadores (HUSSEIN et al., 2015).

A ausência de cuidado por parte das organizações em relação à gestão dos fatores psicossociais de risco à saúde do trabalhador e qualidade de vida no trabalho tem sido apontado por pesquisadores como uma das mais importantes causas do adoecimento neste contexto. Segundo Olivier, Perez e Behr(2011), por exemplo, as estatísticas apontam para o aumento das doenças mentais, sendo que essas são o segundo maior motivo de afastamento de trabalhadores causado por doenças no Brasil, precedido somente de doenças osteomusculares. Esse fato revela, em nossa realidade, o avanço dos transtornos mentais e do comportamento relacionados ao trabalho. A presença desses transtornos, cada vez mais constantes nos âmbitos organizacionais, têm sua gênese em diferentes fatores, especialmente aqueles relacionados à intensificação de cobranças e pressões por produtividade, gerando tensões exageradas, incertezas e inseguranças, como também, a presença de relacionamentos interpessoais conflituosos oriundos de um ambiente cada vez mais competitivo e hostil (BENETTI et al., 2014). Assim, a presença do assédio moral nas organizações de trabalho é apenas um dos sintomas do mal-estar presente em ambientes hostis e que apresentam má gestão organizacional e dos fatores psicossociais de risco, não sendo esta, portanto, a única causa do desencadeamento dos transtornos mentais e do comportamento (BRASIL, 2001).

O presente estudo, realizado mediante levantamento temático na literatura nacional, objetivou discutirarelação do assédio moral praticado nas organizações com eventuais prejuízos à saúde mental do trabalhador, especificamente o episódio depressivo. Com base nos principais indexadores científicos (Scielo, BVS-Psi, PepsiCo e Google 
Scholar) e a partir dos descritores "assédio moral and depressão", com delimitação cronológica até julho de 2018. Entende-se que um quadro depressivo pode ser iniciado e/ou potencializado mediante a degradação da subjetividade do trabalhador e das relações interpessoais que são estabelecidas num ambiente onde prevalece constantes e intensas formas de conflito, em especial o desrespeito, as humilhações e os fatores psicossociais de risco, como anteriormente apresentados. Para além da discussão sobre o assédio moral e sua relação com o adoecimento mental do trabalhador, o texto visou também despertar a atenção dos profissionais que atuam na área da Gestão de Pessoas para esse fenômeno, e assim sendo, possibilitar que os mesmos, uma vez apropriados do conhecimento aqui socializado, passem a planejar políticas e práticas que efetivamente contribuam para a construção e manutenção de ambientes organizacionais de trabalho mais favoráveis à saúde e bem-estar do trabalhador.

\section{Assédio Moral nas Organizações: Compreendendo o Fenômeno}

O primeiro estudo acerca do fenômeno "assédio moral" foi realizado pelo sueco Heinz Leymann, em 1980, demonstrando assim que o tema não é recente na literatura (LEYMANN, 1990 apud CHIAVEGATTO; ALGRANTI, 2013). O autor explica que o assédio moral é um fenômeno no qual uma pessoa ou grupo de pessoas exerce violência psicológica, de forma sistemática e frequente, durante um tempo prolongado, objetivando a destruição das redes de comunicação da vítima ou vítimas, bem como perturbar a realização de seu trabalho até conseguir que as pessoas deixem o local de trabalho, preferencialmente demitindose. Hirigoyen (2014) explica que o assédio moral caracteriza-se por toda e qualquer conduta abusiva por comportamentos, palavras, atos, gestos, que possam trazer dano à personalidade, à dignidade ou à integridade física ou psíquica de uma pessoa.
Segundo Silva et al. (2009), as formas de violência no trabalho são classificadas como violência física ou violência psicológica. A primeira diz respeito ao uso da força física contra uma pessoa ou um conjunto de pessoas, de forma que resulta em prejuízo físico, sexual ou psicológico; a violência psicológica no âmbito do trabalho é expressa pelo uso intencional do poder, o que pode incluir ameaças de força física contra outra pessoa ou grupo, podendo ocasionar danos para o desenvolvimento físico, mental, moral ou social, podendo se caracterizar enquanto agressão verbal, assédio moral, assédio sexual e discriminação racial.

Para Nunes e Tolfo (2013) e Olivier, Perez e Behr (2011), compreender o assédio moral nas organizações demanda o entendimento de que o tema é complexo e multicausal, envolvendo aspectos psicológicos, interpessoais, organizacionais e ambientais. O fator cultural também deve ser considerado na leitura dos casos de assédio moral, sobretudo em se tratando das atuais e cada vez mais comuns fusões e transculturalização das organizações, posto que o que vale para uma determinada cultura e pode ser por ela reconhecido como valor, pode, por outra cultura, ser rejeitado ou mesmo tomado como ofensa. Contudo, o assédio moral organizacional é caracterizado por perseguições, humilhações, constrangimentos e pressões dirigidas a um ou mais trabalhadores de forma repetida, e possuem o intuito de servir de exemplo para os demais membros, na maioria das vezes com o intuito de que estes alcancem, de qualquer forma, as metas e objetivos estabelecidos pela organização (NUNES, 2011; GOSDAL et al., 2009).

Freitas, Heloani e Barreto (2008) mencionam que existem quatro critérios que configuram o assédio moral. O primeiro é a habitualidade e repetitividade, ou seja, ações pontuais não determinam o assédio moral. A violência psicológica deve ocorrer repetidas vezes por um período de tempo. O segundo diz respeito a pessoalidade, onde as práticas hostis 
são dirigidas a uma pessoa em específico. $\mathrm{O}$ terceiro refere-se ao limite geográfico, ou seja, as ações de assédio devem ocorrer no ambiente de trabalho, entre pessoas que pertençam à mesma organização. Por fim, a intencionalidade que caracteriza-se quando o assediador objetiva prejudicar a vítima, tendo em vista a sua retirada ou diminuição de participação em determinados projetos, demissão ou desligamento em outras atividades.

É importante ressaltar que o assédio moral pode ocorrer entre relações de poder nos níveis hierárquicos em sentido vertical, horizontal e descendente. O último caso é o mais habitual, porém, subordinados também podem dirigir humilhações e retaliações a um líder, principalmente quando este é novo na organização. Hussein et al. (2015) e Goulart e Goulart Júnior (2017) discutem o fato de que o assédio moral pode ser mais comum em relações hierárquicas e assimétricas, predominando comportamentos inadequados, relações desumanizadas e atitudes antiéticas por parte do gestor.

Heloani (2004) destaca que o assédio moral é identificado pela intencionalidade, que provoca a desqualificação do indivíduo que sofre a violência, sucedido da consequente fragilização, de maneira que neutraliza a vítima. Destarte, ocorre o enfraquecimento psíquico que pode levar à gradativa despersonalização e ao desenvolvimento de alterações de humor e depressão. Silva et al. (2009) assinala que assédio moral no ambiente organizacional pode gerar consequências aos trabalhadores, tais como acidentes físicos $\mathrm{e}$ sofrimento psíquico. Os autores chamam a atenção para um quadro de sintomas que podem surgir nas pessoas que sofrem o assédio, destacando o desânimo, cansaço constante, ansiedade, estresse, tendência suicida, insegurança, vergonha e hipersensibilidade, todos eles, de certo, impactando negativamente sobre a saúde física e mental dos trabalhadores vitimados.

Seligmann-Silva (2011) explica que o assédio moral nas organizações é configurado quando a dignidade de alguém é atacada de modo repetitivo durante um período prolongado, tendo por objetivos excluir, desqualificar profissionalmente e desestabilizar emocionalmente alguém. A autora também assinala a existência do assédio coletivo, no qual a violência é direcionada a um grupo de pessoas. Neste sentido, o assédio moral ocasiona perda de prestígio e status ao trabalhador, além do mesmo atribuir a si inutilidade e insignificância, sendo que muitos têm vergonha de expor as humilhações sofridas. Heloani (2004) chama a atenção para a diferença entre homens e mulheres no contexto do assédio, argumentando que as mulheres são as que mais sofrem o assédio moral no trabalho (além de também serem mais vitimadas pelo assédio sexual) e destaca, no entanto, que são as mulheres que mais verbalizam sobre essa situação e as que mais procuram ajuda médica e psicológica. Em relação aos homens, no entanto, o autor relata que o assédio fere a identidade masculina, tão valorizada na sociedade ainda machista, o que muitas vezes impede a verbalização da violência. Bobroff e Martins (2013) apresentam um estudo de revisão integrativa confirmando as diferenças entre os sexos. O estudo demonstrou que as mulheres são as que mais sofrem com o assédio moral. Para elas, os abusos e as agressões verbais estão nas piadas grosseiras e na aparência física; já para os homens, nas piadas relacionadas à virilidade, à capacidade de trabalhar e à manutenção da subsistência familiar. Estudos realizados por Pai et al. (2018) que visou analisar a presença de violência física e psicológica em trabalhadores da saúde, também revelou que mulheres foram estatisticamente mais expostas à violência física, assédio moral e discriminação racial.

Não raro, observam Hussein et al. (2015) e Heloani (2004), a percepção do fenômeno assédio ocorre quando o mesmo já se estruturou e fragilizou a vítima, podendo dar início a um estado depressivo a partir do qual o indivíduo não possui forças para reagir frente à situação e, defender-se, portanto. 
Barreto e Heloani (2015) complementam a discussão a partir do pressuposto de que a cultura organizacional contribui e é terreno fértil para a ocorrência do assédio laboral, mesmo que indiretamente e, sobretudo, quando sustenta uma rede de relações interpessoais pautada na competitividade e na relação de poder verticalizada. Seligmann-Silva (2011) aponta para a responsabilidade da organização como um todo nas práticas de assédio moral, de modo que culpabilizar somente um indivíduo ou pequenos grupos especificamente não é cabível, devendose, sempre que possível, levar em consideração a complexidade do fenômeno e sua relação de interdependência com as diversas dimensões do contexto organizacional, a saber: políticas e práticas de gestão; relações de poder; formas de comunicação empregadas; cultura e clima organizacional; valores organizacionais; planejamento estratégico da organização e metodologias de estabelecimento de metas; sistema e políticas de gestão de pessoas; relação da organização com público externo (clientes, fornecedores, sistemas de governo, etc.) (HUSSEIN et al., 2015). Os autores supracitados acrescentam que o assédio moral possui início com um ato de intolerância - produto de uma construção social em que é reproduzida no microespaço das organizações - transformada em perseguição, isolamento, negação de comunicação, sobrecarga ou esvaziamento de responsabilidades e grande dose de sofrimento.

Dentro deste contexto de assédio relacionado ao trabalho, Seligmann-Silva (2011) traz uma contribuição importante, uma vez que correlaciona a fadiga, a diminuição da disposição à sociabilidade e o desgaste psíquico às práticas de assédio moral, o que é capaz de ocasionar o isolamento social do trabalhador, bem como a diminuição de sua autoestima; no cenário do assédio, muitas vezes, o indivíduo perde forças e não consegue reagir a tal situação. Outro aspecto discutido pela autora é a distinção entre assédio organizacional e assédio nas organizações. O assédio organizacional, comumente utilizado,éoresultadodas estratégias organizacionais que sobrecarregam os trabalhadores a fim de maximizar os lucros e aumentar a produtividade. Contudo, o assédio nas organizações refere-se aos próprios trabalhadores praticarem as ações violentas sem que, necessariamente, a organização apresente políticas internas e estratégicas que ferem a dignidade do trabalhador. Entretanto, entende-se a dificuldade de se fazer essa distinção, sobretudo considerando que o comportamento humano no trabalho recebe forte influência de fatores da micro e da macro cultura organizacional predominante. Soboll (2008) explica que o assédio moral pode envolver duas perspectivas: a do assédio pessoal envolvendo as questões de relações interpessoais no contexto; e o assédio organizacional, mais associado a demandas do contexto de trabalho, processos e aspectos relativos às políticas de gestão. Na direção de se buscar uma adequada compreensão sobre as causas do assédio moral e posterior planejamento de intervenções, Rissi et al. (2016) destacam a importância de se levantar informações sobre essas duas perspectivas, ou seja, das relações de trabalho e da organização onde os trabalhadores atuam.

Embora haja no Brasil uma legislação que pune atos de assédio moral nas organizações, a medida remediativa não é suficiente, o que demanda ações preventivas principalmente em relação ao comportamento dos gestores. Nesta lógica, Penteado et al. (2011) ressaltam a importância do papel do líder, posto que se ele direciona condutas expositivas e humilhantes a um trabalhador, esse comportamento pode ser repetido individualmente ou compartilhado por todo o grupo tendo em vista a influência e a relação de poder canalizada nas figuras de lideranças, o que pode favorecer situações hostis de maiores proporções. Silva, Castro e Dos-Santos (2018) em estudo que investigou a relação entre cultura organizacional, assédio moral e satisfação no trabalho, dentre suas descobertas, evidenciaram que a cultura organizacional apresenta um papel relevante no aparecimento ou manutenção do assédio moral nos contextos pesquisados. Assim 
sendo e considerando que as lideranças exercem papel fundamental na criação e manutenção da cultura organizacional, essa categoria profissional ganha ainda mais importância no tocante a sua influência na presença do assédio moral nos contextos organizacionais.

Andrade e Assis (2018) e Glina e Soboll (2012), em estudos de revisão bibliográfica integrativa que buscaram compreender o assédio moral no trabalho na produção científica brasileira nas áreas de educação e saúde, identificaram que, a maioria dos estudos e pesquisas apresentadas na revisão corroboraram com a literatura, reiterando a influência do assédio moral no trabalho como fator de influência na saúde das pessoas envolvidas e, dentre outros achados, encontraram correlação positiva entre assédio moral no trabalho e a presença da depressão nos indivíduos. A OMS (2004), em consonância aos estudos supracitados, afirma haver nexo causal entre assédio moral e episódios depressivos no trabalho.

Considerar as condições de assédio moral com uma possível relação com o favorecimento da presença de episódios depressivos nos trabalhadores assediados, torna-se um desafio considerável, por tratar-se de dois fenômenos complexos e multideterminados. No entanto, iniciar e fomentar essa discussão, representa um passo importante na compreensão dos impactos que o assédio pode trazer a saúde e bem estar do trabalhador, especialmente no tocante a presença dos episódios depressivos.

\section{Episódios Depressivos e a Saúde do Trabalhador: Algumas Considerações}

Aincidênciadeacentuadas exigências referentesà qualificação para o trabalho, bem como o aumento no ritmo das atividades realizadas pelos trabalhadores, pluralidade de tarefas exigidas, o medo da demissão a qualquer momento, crescentes cobranças por aumento de produtividade e cumprimento de metas, entre outras situações já apresentadas, são realidades nos contextos organizacionais atuais. Essas situações, muitas vezes, são vivenciadas silenciosamente. A sobrecarga, principalmente mental, evidencia-se neste cenário no qual o adoecimento físico e os transtornos psíquicos são quase inerentes, em maior ou menor grau. Para Xavier et al. (2008), o sofrimento relacionado ao trabalho pode ser resultado de fatores tais como ritmo intenso das jornadas, com poucas pausas, pressões das lideranças pelo alcance de metas e maior produtividade, entre outros; uma menção resumida àqueles fatores psicossociais anteriormente apresentados e que interferem significativamente na qualidade de vida no trabalho e, consequentemente, na saúde dos trabalhadores (CARDOSO; FEIJÓ; CAMARGO, 2018).

O Ministério da Saúde do Brasil e a Organização Pan-Americana da Saúde(BRASIL, 2001), de acordo com a Portaria $\mathrm{n}^{\circ} 1.339$, de 18 de novembro de 1999 , reconhecem e apresentam 12 transtornos mentais e do comportamento relacionados ao trabalho, sendo eles : a) demência em outras doenças específicas classificadas em outros locais; b) delirium, nãosobreposto à demência; c) transtorno cognitivo leve; d) transtorno orgânico de personalidade; e) transtorno mental orgânico ou sintomático; f) alcoolismo crônico; g) episódios depressivos; h) estado de estresse pós-traumático; i) neurastenia; j) outros transtornos neuróticos especificados; k) transtorno do ciclo vigília-sono devido a fatores não orgânicos; 1) síndrome de burnout ou síndrome do esgotamento profissional. Destacar-se-á, visando atender os objetivos propostos em nosso trabalho, os episódios depressivos oriundos do trabalho, embora entenda-se a importância de se atribuir atenção a todos os demais transtornos mentais relacionados ao trabalho, já reconhecidos pelos órgãos competentes.

Segundo Silva et al. (2009), a depressão está relacionada ao estresse, ao esgotamento e à falta de prazer, bem como à baixa satisfação profissional. Os autores chamam a atenção pelo fato de que, muitas vezes, a apatia gerada pela situação impossibilita o 
indivíduo de buscar estratégias de enfrentamento do mal estar vivenciado. Ainda para os autores, o trabalhador com depressão apresenta elevadas taxas de erros nas tarefas, lentidão, dificuldades de concentração e atrasos em compromissos.

De modo amplo, a depressão pode ser classificada como leve, moderada ou grave, sendo que há perda de interesse da pessoa em atividades que antes eram prazerosas, além da redução de energia e concentração, aumento do cansaço, angústia, ideias de inutilidade e visão pessimista em relação ao futuro. O DSM - V (APA, 2013) propõe critérios diagnósticos para o Transtorno de Depressão. Primeiramente, cinco ou mais dos sintomas dispostos a seguir devem estar presentes por pelo menos duas semanas, representado mudanças no funcionamento prévio do indivíduo. Deve-se atentar ao fato de que estas condições podem estar relacionadas a outra condição clínica, assim, o diagnóstico diferencial deve ser realizado. São eles: (1) humor deprimido na maioria dos dias, quase todos os dias; (2) acentuada diminuição do prazer ou interesse em todas ou quase todas as atividades na maior parte do dia, quase todos os dias; (3) perda ou ganho de peso acentuado sem estar em dieta, ou aumento ou diminuição de apetite quase todos os dias; (4) insônia ou hipersônia quase todos os dias; (5) agitação ou retardo psicomotor quase todos os dias; (6) fadiga e perda de energia quase todos os dias; (7) sentimento de inutilidade ou culpa excessiva ou inadequada quase todos os dias; (8) capacidade diminuída de pensar ou concentrar-se ou indecisão quase todos os dias; (9) pensamentos de morte recorrentes (não apenas medo de morrer), ideação suicida recorrente sem um plano específico, ou tentativa de suicídio ou plano específico de cometer suicídio. Além disso, os sintomas devem causar sofrimento clinicamente significativo ou prejuízos no funcionamento social, ocupacional ou em outras áreas importantes da vida do indivíduo. Assim sendo, deve-se considerar o fato de que os sintomas da depressão não são isolados, ou seja, mantém conexão com outras dimensões do existir humano, podendo afetar mais áreas da vida privada do indivíduo, principalmente na dinâmica familiar e vida profissional.

Segundo a Organização Mundial da Saúde (OMS, 2008), a pessoa deprimida pode apresentar sintomas tais como a diminuição de humor e perda de energia e interesse em atividades que antes eram prazerosas. Ocorre também a redução da capacidade de concentração, comumente relacionado à fadiga. Tais sintomas podem ser acompanhados da diminuição da autoestima e autoconfiança, além de ideias de culpabilidade. Os sintomas fisiológicos, do mesmo modo, estão presentes em quadros depressivos, a exemplo de problemas com o sono, redução do apetite, perda da libido e lentidão psicomotora.

Tendo em vista o contexto de trabalho, Seligmann-Silva (2011) explica que a depressão pode ser produzida em contextos nos quais há frustração, perda de sentido nas atividades laborais, humilhações constantes, autodesvalorização profissional e vivências de fracasso, em que há um processo gradativo de empobrecimento e esvaziamento do significado do trabalho. Considerando-se a conjuntura inconstante, característica do mundo do trabalho atual, o medo frequente de ser demitido, também está associado ao desenvolvimento de quadros depressivos. A mesma autora pontua que nos quadros depressivos típicos:

[...] surgem claramente as manifestações de desânimo, tristeza, autodesvalorização; os pensamentos mórbidos, as vivências de perda ou fracasso e mesmo ideias de total e irremediável ruína de si mesmo. A insônia ocorre geralmente e concorre para agravar a fadiga. A percepção de lentificação do pensamento desperta angústia, assim como todas as outras inibições e bloqueios percebidos pelo trabalhador em si mesmo. As dificuldades em manter comunicação com os demais, participar nas atividades sociais, juntamente com a percepção de impossibilidade de manter o ritmo de trabalho, constituem, em geral, uma característica bem evidente nesses casos. Um componente frequente da dinâmica 
psíquica é, nesse caso, a autoculpabilização pelos insucessos percebidos (SELIGMANN-SILVA, 2011, p. 532).

Outro ponto acerca da associação entre trabalho e depressão é abordado por Jardim (2011), que teoriza sobre a relação entre o trabalho e a identidade humana, defendendo que as atividades laborais constituem o laço simbólico entre o individual e a ordem coletiva. Para a autora, uma vez que este laço é abalado por ações e políticas organizacionais que ferem o sujeito de algum modo, o valor do trabalho e a subjetividade do indivíduo também entram em colapso. Assim, reforça-se o pressuposto de que o trabalho é constituinte da subjetividade humana, sendo que qualquer prática violenta nas organizações incide diretamente na saúde psíquica do trabalhador de maneira negativa.

\section{Assédio Moral como Possível Potencializador de Episódios Depressivos}

A literatura dispõe de modesta quantidade de textos correlacionando de modo direto o assédio moral nas organizações e episódios depressivos, muito embora trate abundantemente destes temas de forma individualizada. Contudo, realizar esta relação é possível a partir dos conceitos expostos ao longo do texto, como também a análise dos estudos na área que serão apresentados na sequência.

Anterior à discussão proposta nesta parte do texto, torna-se relevante explanar um conceito de psiquismo que auxiliará o entendimento da relação entre assédio moral e estados depressivos. A obra de Vigotski (1988 apud MARTINS; RABATANI, 2011) orienta-se no pressuposto de que o psiquismo é fruto de relações sociais internalizadas pelo indivíduo. A lei genética geral do desenvolvimento psíquico aponta para esta correlação, explicitando que a individualidade e subjetividade humana ocorre, primeiramente, no plano social e depois no plano psicológico, ao passo que o interpsíquico (relações sociais) antecede e retroage no intrapsíquico. Neste sentido, as condições objetivas encontradas pelo sujeito e todo discurso social sobre o mesmo incide diretamente em sua constituição subjetiva. $\mathrm{O}$ assédio moral, enquanto fenômeno de intersecção sócio-moral com o campo subjetivo do trabalhador em sua relação com o trabalho e a com a organização pode ser incluído neste pressuposto, uma vez que as condições hostis de trabalho e o discurso violento proferido contra o trabalhador acomete sua subjetividade.

Dejours (2008), partindo do referencial psicanalítico, comenta que o assédio moral é uma das práticas que podem ocasionar o sofrimento no ambiente de trabalho. Além disso, o crescimento destas práticas que têm levado a patologias relacionadas ao trabalho é um fato preocupante. $\mathrm{O}$ autor ressalta que o individualismo e falta de solidariedade entre os trabalhadores pode estar relacionada a este cenário violento no ambiente organizacional. Soares e Oliveira (2012) apresentam como consequências do assédio moral quadros de depressão e ansiedade, dificuldades no sono, estresse pós-traumático e suicídio.

Santos, Siqueira e Mendes (2010) identificaram correlação positiva entre o assédio moral e depressão em trabalhadores que atuam no setor bancário, em decorrência do mesmo ser caracterizado por muita instabilidade e pressão exacerbada na atualidade. Comoconsequênciadeumareestruturaçãoprodutiva, um banco brasileiro (que por questões éticas teve sua identificação omitida) registrou aumento significativo de afastamentos de trabalhadores por motivos de transtorno mental e/ou comportamental, em especial, a depressão. Considerando seu contexto de transição, decisões de remodelação estrutural (demissões, fechamento de agências, redistribuição de funções, transferências de pessoal, mudanças de líderes, redefinição de metas, etc.) e mediante às condições de trabalho delas resultantes, o que implicou em diminuição de qualidade de vida no trabalho, os autores identificaram a presença de comportamentos de retaliação e relação interpessoal desarmoniosa entre os trabalhadores do banco, ou 
seja, uma deterioração das relações humanas no trabalho.

Nesta linha de pensamento, surge outra questão relacionada à depressão - em seu nível mais severo - o suicídio decorrente do trabalho. Reitera-se que a doença mental referente ao trabalho é decorrente de amplos fatores, sendo que um deles é o assédio moral. Associado ao trabalho fragmentado, com pouca significação, chefia autoritária, excesso de trabalho ou o contrário - visto que em alguns ambientes o líder priva o trabalhador de certas atividades - e prática de Gestão de Pessoas inexistentes para prevenir ou mudar a situação degradante de trabalho, contribuem para a deterioração psíquica do indivíduo. Além do mais, o fenômeno se torna cíclico, pois as dificuldades iniciais desencadeiam um processo de piora sucessiva das condições de trabalho, em que os afastamentos para tratamento médico, principalmente em decorrência de transtornos mentais, são interpretados como se o trabalhador não estivesse mais apto ao enfrentamento do cotidiano laboral, aumentando ainda mais o isolamento social, o sentimento de inutilidade e o desgaste psicológico (SANTOS; SIQUEIRA; MENDES, 2010).

Conforme já retratado, o assédio moral nas organizações deixa marcas na subjetividade do trabalhador, que muitas vezes se sente impotente diante da situação e sofre com a violência, porém nada podendo fazer para revertê-la. As marcas deixadas são produto da internalização do discurso humilhante dirigido ao indivíduo, tomando para si como verdadeiro o que foi dito pelo agressor. Reiterando o que Seligmann-Silva (2011) discorre diante do assédio nas organizações, as atividades laborais aos poucos perdem sentido para o trabalhador e há o esvaziamento do significado do trabalho, cuja importância na constituição psíquica é incomensurável. Além disso, a impotência, ao mesmo tempo, fragiliza o trabalhador, o qual muitas vezes não consegue expressar ou falar sobre os acontecimentos vivenciados e, gradativamente, leva ao isolamento social. As consequências desse cenário estendem-se para além do contexto do trabalho, podendo interferir negativamente em outras esferas de vida do indivíduo, especialmente na dinâmica familiar, impactando no desejado e adequado equilíbrio entre as exigências do trabalho e os familiares.

Explicitou-se nas reflexões e argumentos trazidos até aqui, que o autor do assédio moral desqualifica a vítima, colocando-a numa posição de inferioridade em relação aos demais, de modo que este discurso proferido continuamente pode levar a vítima a acreditar que seu trabalho é inútil dentro da organização. É interessante ressaltar que ao perceber seu trabalho como inútil, o indivíduo pode sentir-se inútil, acometendo-o no âmbito da subjetividade, podendo, a partir disso, surgir sentimentos negativos sobre si. Instala-se, portanto, um sentimento de inferioridade e incapacidade, podendo dar início ao desencadeamento de um processo depressivo. $\mathrm{O}$ ambiente hostil encontrado pelo sujeito torna-se desmotivador, diminuindo o prazer e a vontade de frequentar o ambiente de trabalho e realizar suas atividades profissionais. Conforme já descrito, o indivíduo que sofre o assédio moral comete mais erros de execução de tarefas do trabalho, culminando em mais humilhações e, consequentemente, à exaustão e fadiga do trabalhador. Instala-se assim, um ciclo perverso e desumano.

Deste modo, constata-se que os sintomas produtos do assédio moral, tais como: sentimentos negativos sobre si, sentimentos de inutilidade, diminuição do prazer na realização de atividades, fadiga e exaustão são também característicos dos quadros de episódios depressivos. SeligmannSilva (2011) já indica isso quando argumenta que o assédio moral é capaz de ocasionar o isolamento social do trabalhador, bem como a diminuição de sua autoestima, cujas consequências estão diretamente correlacionadas à depressão. Silva et al. (2009) explica que as vítimas de assédio moral podem apresentar desânimo, cansaço, ansiedade, 
estresse, tendência suicida, insegurança, vergonha e hipersensibilidade, cujas consequências incidem sobre o trabalho, tendo em vista que as atividades laborais exigem certa energia que, muitas vezes, está sendo aniquilada aos poucos em decorrência da violência psíquica (CAMARGO, 2017; GONDIM; SIQUEIRA, 2014; COSTA; SANTOS, 2013). Para além disso, importa ressaltar que os sintomas ideação suicida, desânimo e hipersensibilidade caracterizam os episódios depressivos (JARDIM, 2011).

Outro ponto importante assenta-se sobre o fato de que, uma vezque otrabalhadorencontra-seacometido pela depressão, um processo de retroalimentação se instaura paralelamente, ou seja, o estado depressivo impede que o indivíduo tenha ânimo e força para enfrentar a situação, o que pode culminar com ainda mais humilhações e constrangimentos, favorecendo uma mais significativa vulnerabilidade psíquica ao trabalhador, que por não conseguir sair ou lidar com a situação, fica, por mais tempo, exposto ao contexto de assédio.

Muitas das relações explicitadas acima dizem respeito diretamente à área profissional do indivíduo. Diante disso, torna-se relevante compreender que o homem é um sujeito único e integrado, e o que recai sobre o âmbito profissional incide diretamente em sua vida pessoal, familiar e social, tendo em vista que o trabalho constitui a subjetividade humana. Uma referência importante relacionada a esta questão é discutida por Martins (2007), cujo estudo mostra que a atividade de trabalho é caracterizada por um conjunto de ações orientadas por motivos e realizadas no atendimento às finalidades das ações; uma vez que o trabalho perde sentido ou significado ele é configurado como trabalho alienado. O trabalho alienado provoca esvaziamento, empobrecimento e não engrandece o homem, porém, pode acarretar em grande sofrimento ao mesmo. Diante disso, ações devem ser tomadas para que o trabalho seja edificante ao homem e contribua para seu processo de desenvolvimento constante.

\section{O Papel das Políticas e Práticas de Gestão de Pessoas na Prevenção e Promoção da Saúde do Trabalhador}

$\mathrm{O}$ assédio moral emerge enquanto problema social, cujo reflexo incide nas formas de gestão organizacionais. O problema é estrutural e a compreensão acerca do tema abarca os diversos âmbitos da vida na sociedade contemporânea. Gonçalves e Schweitzer (2017) discutem que a prevenção do assédio deve ocorrer, principalmente, mediante a criação de políticas públicas, além de repensar a cultura organizacional e o modelo de gestão que propiciam as ações violentas. Ressaltase a importância de pensar o papel dos gestores neste contexto de assédio moral, que muitas vezes são os protagonistas das práticas violentas ou então omissos. O gestor é peça chave ao pensar a prevenção de comportamentos violentes e hostis nas organizações de trabalho. Em pesquisa realizada com Psicólogos atuantes em organizações de trabalho, Rissi et al. (2016) buscaram compreender como estes profissionais enfrentavam o assédio moral e conseguiram evidenciar a existência de uma preocupação dos mesmos com a capacitação das lideranças e gestores para o estabelecimento de relações mais respeitosas com seus subordinados mediante uma comunicação assertiva e práticas adequadas de feedback.

Chiavegatto e Algranti (2013) explicitam que o momento atual relacionado à saúde do trabalhador deve possuir foco na prevenção e promoção da saúde, demandando um planejamento estratégico de âmbito nacional e de políticas públicas, bem como aquelas que incidirão sobre as organizações, cada qual com sua identidade, missão, visão, características e valores muito particulares. Para os autores, a atenção à saúde do trabalhador contempla três níveis de atuação: a vigilância, a qual inclui as ações destinadas à definição dos perigos e dos riscos inerentes ao processo de trabalho e a promoção de práticas que tenham por objetivo o controle destes perigos e riscos; a assistência à saúde, que inclui 
serviços de acolhimento, atenção, condutas clínicas e ocupacionais e um sistema justo de benefícios; e a abordagem e as condutas apropriadas aos determinantes sociais, individuais ou de grupos, que impactam negativamente na saúde da maioria dos trabalhadores.

Considerando esta discussão, pode-se postular que a atuação de profissionais da área da saúde no espaço das organizações é de grande importância, tanto no combate quanto na prevenção do adoecimento psíquico do trabalhador, de modo que a realização contínua de diagnósticos organizacionais e ações que promovam o clima de trabalho satisfatório são exemplos de práticas que favorecem a saúde do trabalhador, em especial porque possuem função preventiva (SILVA et al., 2009). Os mesmos autores afirmam ainda que os estilos de lideranças são importantes fatores que influenciam no ambiente de trabalho e nas relações interpessoais que ali se dão, os quais podem caracterizar-se pelo autoritarismo e centralização de poder, sendo que este estilo de liderança pode levar "à diminuição da motivação, ao descontentamento e ao baixo grau de integração, elementos diretamente ligados à ansiedade, a comportamentos problemáticos, à depressão, entre outros" (SILVA et al., 2009, p. 7). De maneira contrária, a liderança democrática/participativa pode gerar segurança e autonomia nas equipes de trabalho, fortalecendo as emoções positivas, contribuindo para o sentimento de pertencimento à organização, comportamentos cooperativos e relações interpessoais mais saudáveis, o que, consequentemente, diminui a ansiedade e configura um quadro propício para a busca e a aquisição de novas competências.

A área de Gestão de Pessoas deve ser estratégica, diagnosticando possíveis práticas violentas e agressivas, bem como prevenindo tais ações. A disseminação da cultura organizacional e a criação de um código de conduta são ações interessantes de serem desenvolvidas, visto que a organização deixará claro aos trabalhadores os comportamentos esperados e que devem ser seguidos de acordo com os valores da mesma. Por outro lado, uma mudança de mentalidade faz-se necessária quando a cultura da violência e opressão estão instituídas e naturalizadas na organização, fato este facilmente identificado através de um diagnóstico do clima organizacional. O papel de lideranças assertivas e que produzam um ambiente cooperativo e saudável de trabalho é um ponto a ser explorado quanto à prevenção do assédio moral e, consequentemente, na prevenção de transtornos mentais dele oriundos.

O modelo de liderança desejada nas relações de trabalho contemporâneas deve identificar quais são as necessidades do trabalhador e agir em direção a saná-las, bem como criar um cenário de comunicação no qual os ruídos são amenizados e os conflitos são prevenidos ou resolvidos de maneira sensata. Além disto, o líder deve contribuir para que as relações de trabalhos sejam mais transparentes e humanizadas, premissas essenciais para a promoção de saúde no trabalho. Cabe aos profissionais de Gestão de Pessoas, mediante ações formais e informais, atuarem na direção de planejar e executar programas de educação continuada, preparando e capacitando as lideranças para essa conduta.

As políticas e práticas de gestão organizacional, principalmente de Gestão de Pessoas, precisam alinhar-se na busca de um ambiente corporativo mais saudável, humano e justo, diagnosticando de forma contínua situações que não se compatibilizam com isso. Fomentar a cultura da prevenção também se configura como importante estratégia de gestão, antecipando-se a situações que, se presentes, poderão impactar negativamente na qualidade de vida no trabalho, bem estar do trabalhador e na saúde da própria organização. Discutir e refletir sobre o assunto é de suma importância na prevenção do assédio moral, informando sobre o fenômeno para os trabalhadores, suas causas e consequências. Nessa questão, o papel dos profissionais que atuam em Gestão de Pessoas também ganha destaque. Faz-se importante a compreensão de que essas ações terão reflexos significativos nos resultados organizacionais, tornando a organização melhor 
preparada para atuar em um cenário de instabilidade e acentuada competitividade. Tal posicionamento encontrasse corroborado por Soboll (2017) e Rissi et al. (2016).

\section{Considerações Finais}

O presente texto, muito longe de querer esgotar o assunto que aborda, traz à baila um tema de significativa relevância nos âmbitos individual, organizacional e social, iniciando reflexões e considerações sobre a associação entre assédio moral e o transtorno depressivo; dois fenômenos importantes considerando as consequências que trazem para vida das pessoas e na sua interação com as diferentes esferas de vida, aqui, especificamente, na sua relação com o trabalho. As considerações apresentadas no texto pretenderam fomentar maiores discussões sobre o assédio moral no trabalho e suas consequências, o que, por si só, já justificaria sua redação.

$\mathrm{O}$ presente estudo permitiu ainda um reconhecimento da literatura brasileira acerca do assédio moral e do fato de que as consequências destas práticas para a saúde do trabalhador estão recebendo atenção mais recentemente. Medidas preventivas e o papel da área de Gestão de Pessoas em relação ao tema é quase inexistente na literatura, demandando mais estudos e produções científicas sobre o mesmo. A visão do papel de políticas e práticas de Gestão de Pessoas como estratégica é fundamental neste cenário de violência velada, visto que as situações de assédio ocorrem com mais frequência em contextos de trabalho onde prevalece uma cultura organizacional que não incentiva, mas é conivente com o assédio moral, causando prejuízos psíquicos para o trabalhador (adoecimento) e para a organização (absenteísmo, presenteísmo, rotatividade, diminuição de produtividade, etc.).
O mundo do trabalho sofreu e sofre modificações ao longo do tempo, o que lhe é inerente tendo em vista as mudanças sociais, políticas, tecnológicas e econômicas globais. Diante disso, a organização de trabalho, para além da preocupação com o aumento da produtividade e da lucratividade, deve direcionar atenção constante para a situação na qual os trabalhadores encontram-se, pois são eles os principais atores do êxito e resultados das organizações.

Sabe-se que o assédio moral manifesta-se como um dos sintomas da má gestão organizacional, de modo que a correlação com a depressão é apenas um recorte, visto que a doença mental, ao mesmo tempo, é decorrente de diversos fatores, sendo que o trabalho, pela sua importância para as pessoas e considerando o tempo que essas dedicam a ele, é um fator contribuinte para o seu desenvolvimento. Porém, é importante pensar nestas práticas hostis e violentas e, consequentemente, sobre sua incidência negativa na subjetividade do trabalhador. É importante frisar que o assédio moral ocorre quando as humilhações, pressões, xingamentos, etc., são constantes, e não produto de situações esporádicas, ou seja, ele pode estar sendo, por algumas organizações e por gestores organizacionais, sendo utilizado como dispositivo velado em prol de um aumento de ritmo, de produtividade, de ampliação de tempo de dedicação ao trabalho e, metaforicamente falando, um tripalium ${ }^{4}$ pós-moderno.

Deste modo, a depressão é produzida paulatinamente, à medida que vão ocorrendo as degradações do ambiente de trabalho e das interações sociais que são ali estabelecidas, em especial, e como discutido, por meio da má gestão dos fatores psicossociais de risco à saúde do trabalhador e qualidade de vida no trabalho. Neste sentido, a Psicologia, e em especial a Psicologia Organizacional e do Trabalho, presente na área de

4 Tripalium, palavra latina utilizada para nominar um instrumento de tortura, utilizado para açoitar escravos e prisioneiros na Roma antiga e Inquisição. O termo dá ainda origem à palavra trabalho, como demonstra Bonzatto (2011). 
Gestão de Pessoas tem muito a contribuir, visto que seu objeto de estudo principal é o comportamento humano no contexto organizacional de trabalho e as suas correlações com a saúde do trabalhador; o que também envolve discutir e atuar sobre temas como: prazer e sofrimento, abrindo novos espaços para a ciência psicológica atuar não só no bem-estar do trabalhador, mas na visão deste como ser humano que merece condições dignas de vivência do e no trabalho. Assim sendo, todos saem ganhando: trabalhadores, organizações e sociedade.

Nesse cenário de incertezas, instabilidades, cobranças excessivas e da presença cada vez maior do assédio moral nas organizações de trabalho, destaca-se o comportamento do gestor, considerando que esse tem forte influência na cultura organizacional e que essa cultura pode exercer correlação positiva com a presença do assédio moral. Portanto, a maneira como o gestor atua e deixa atuar, tem impactos significativos na presença e manutenção do assédio moral dentro dos contextos de trabalho, cabendo as políticas e práticas de gestão de pessoas, atuarem para preparálos e capacitá-los para o estabelecimento de relações interpessoais assertivas e adequadas junto aos seus subordinados e pares, contribuindo assim para um clima organizacional mais favorável e respeitoso nesses contextos. A sensibilidade do gestor no trato com as pessoas é, portanto, fator determinante para a prevenção do assédio moral nas organizações.

\section{Referências}

ANDRADE, C. B.; ASSIS, S. G. Assédio moral no trabalho, gênero, raça e poder: revisão de literatura. Revista Brasileira de Saúde Ocupacional, São Paulo, v. 43, n. 11, p. 1-13, 2018. Disponível em: <http://www. scielo.br/pdf/rbso/v43/2317-6369-rbso-43-e11.pdf>. Acesso em: 4 set. 2018. http://dx.doi.org/10.1590/23176369000012917

APA - AMERICAN PSYCHIATRIC ASSOCIATION. $D S M-V-T R$ : manual diagnóstico estatístico de transtornos mentais. Porto Alegre: Artes Médicas, 2013.

BARRETO, M.; HELOANI, R. Violência, saúde e trabalho: a intolerância e o assédio moral nas relações laborais. Serviço Social e Sociedade, São Paulo, n. 123, p. 544-561, jul./set. 2015. Disponível em: <http://www. scielo.br/pdf/sssoc/n123/0101-6628-sssoc-123-0544. pdf $>$. Acesso em: 23 jul. 2018. http://dx.doi. org/10.1590/0101-6628.036

BENDASSOLLI, P. F. Psicologia e trabalho: apropriações e significados. São Paulo: Cengage Learning, 2009.

BENDASSOLLI, P. F.; BORGES-ANDRADE, J. E. Significado do trabalho nas indústrias criativas. Revista de Administração de Empresas, São Paulo, v. 51, n. 2, p. 143-159, abr. 2011. Disponível em: <http:// www.scielo.br/pdf/rae/v51n2/v51n2a03.pdf $>$. Acesso em: 23 jul. 2018. http://dx.doi.org/10.1590/S003475902011000200003

BENETTI, C. et al. A importância de ações estratégicas de gestão de pessoas no manejo do estresse e de estressores ocupacionais. OMNIA Saúde, Adamantina, v. 11, n. 2, p. 9-24, 2014. Disponível em: <https:// repositorio.unesp.br/bitstream/handle/11449/135455/ I S S N 2236 - 188 X - $2014-11$ - $02-09$ - 24 . pdf? sequence $=1 \&$ isAllowed $=\mathrm{y}>$. Acesso em: 23 jul. 2018.

BERNAL, A. O. Psicologia do trabalho em um mundo globalizado: como enfrentar o assédio psicológico e o estresse no trabalho. Porto Alegre: Artmed, 2010.

BEUREN, I. M.; AMARO, H. D.; SILVA, P. Y. C. Percepção dos gestores em relação ao princípio da controlabilidade para o alcance da justiça organizacional. REAd: Revista Eletrônica de Administração, Porto Alegre, v. 21, n. 2, p. 378-405, ago. 2015. Disponível em: <http://www.scielo.br/pdf/read/v21n2/1413-2311read-21-02-00378.pdf $>$. Acesso em: 15 jun. 2018. http:// dx.doi.org/10.1590/1413-2311.0502014.53640

BOBROFF, M. C. C.; MARTINS, J. T. Assédio moral, ética e sofrimento no trabalho. Revista Bioética, Brasília, v. 21, n. 2, p. 251-258, ago. 2013. Disponível em: $<$ http://www.scielo.br/pdf/bioet/v21n2/a08v21n2.pdf>. Acesso em: 3 set. 2018. http://dx.doi.org/10.1590/S198380422013000200008

BONZATTO, E. A. Tripalium: o trabalho como maldição, como crime e como punição. Direito em Foco, Registro, v. 1, p. 1-37, 2011. Disponível em: <http://unifia.edu.br/ revista_eletronica/revistas/direito_foco/artigos/ano2011/ Direito_em_foco_Tripalium.pdf $>$. Acesso em: 15 jun. 2018.

BRASIL. Ministério da Saúde. Doenças relacionadas ao trabalho: manual de procedimentos para os serviços de saúde. Brasília, DF, 2001. (Série A: normas e manuais técnicos, 114). 
CAMARGO, M. L. Presenteísmo: denúncia do mal-estar nos contextos organizacionais de trabalho e de riscos à saúde do trabalhador. Revista Laborativa, Assis, v. 6, n. 1 (esp.), p. 125-146, abr. 2017. Disponível em: <http:// ojs.unesp.br/index.php/rlaborativa/article/view/1601>. Acesso em: 23 jul. 2018.

CARDOSO, H. F.; FEIJÓ, M. R.; CAMARGO, M. L. O papel do psicólogo organizacional e do trabalho (POT) na prevenção dos fatores psicossociais de risco. In: SCHMIDT, M. L. G.; CASTRO, M. F.; CASADORE, M. M. Fatores psicossociais e o processo saúde/doença no trabalho: aspectos teóricos, metodológicos, interventivos e preventivos. São Paulo: FiloCzar, 2018. p. 111-136.

COSTA, L. S.; SANTOS, M. Fatores psicossociais de risco no trabalho: lições aprendidas e novos caminhos. International Journal on Working Conditions, Porto, n. 5, p. 39-58, June 2013. Disponível em: $<$ http://laboreal. up.pt/files/articles/39_49.pdf>. Acesso em: 15 jun. 2018.

CHAMBEL, M. J. Gestão de recursos humanos nos trabalhadores temporários de agência. Psicologia: Teoria e Pesquisa, Brasília, v. 31, n. 2, p. 269-278, jun. 2015. Disponível em: <http://www.scielo.br/pdf/ ptp/v31n2/0102-3772-ptp-31-02-0269.pdf>. Acesso em: 15 jun. 2018. http://dx.doi.org/10.1590/010237722015020919269278

ChiaVegatto, C. V.; Algranti, E. Políticas públicas de saúde do trabalhador no Brasil: oportunidades e desafios. Revista Brasileira de Saúde Ocupacional, São Paulo, v. 38, n. 127, p. 25-27, jun. 2013. Disponível em: $<$ http://www.scielo.br/pdf/rbso/v38n127/v38n127a05. pdf $>$. Acesso em: 23 jul. 2018. http://dx.doi.org/10.1590/ S0303-76572013000100005

DEJOURS, C. A loucura do trabalho: estudo de psicopatologia do trabalho. 5. ed. São Paulo: Cortez; Oboré, 1992.

DEJOURS, C. Addendum: da psicopatologia à psicodinâmica do trabalho. In: LACMAN, S.; SZNELWAR, L. (Org.). Cristophe Dejours: da psicopatologia à psicodinâmica do trabalho. 2. ed. Rio de Janeiro: Paralelo 15; Brasília: Fiocruz, 2008. p. 49-106.

DEJOURS, C.; ABDOUCHELI, E.; JAYET, C. (Org.). Psicodinâmica do trabalho: contribuições da escola dejouriana à análise da relação prazer, sofrimento e trabalho. São Paulo: Atlas, 2007.

FERNANDES, E. Qualidade de vida no trabalho. Salvador: Casa da Qualidade, 1996.

FLORES, L. I. et al. O absenteísmo enquanto indicador para o processo de gestão de pessoas nas organizações e de atenção à saúde do trabalhador. Revista Laborativa, Assis, v. 5, n. 2, p. 45-63, out. 2016. Disponível em:
$<$ http://ojs.unesp.br/index.php/rlaborativa $>$. Acesso em: 23 jul. 2018.

FREITAS, M. E.; HELOANI, J. R.; BARRETO, M. Assédio moral no trabalho. São Paulo: Cengage Learning, 2008.

GLINA, D. M. R.; SOBOLL, L. A. P. Intervenções em assédio moral no trabalho: uma revisão da literatura. Revista Brasileira de Sáude Ocupacional, São Paulo, v. 37, n. 126, p. 269-283, dez. 2012. Disponível em: $<$ http://www.scielo.br/pdf/rbso/v37n126/a08v37n126. pdf $>$. Acesso em: 5 set. 2018. http://dx.doi.org/10.1590/ S0303-76572012000200008

GONÇALVES, J.; SCHWEITZER, L. Assédio moral em organizações públicas e a (re)ação dos sindicatos. Revista Psicologia: Organizações e Trabalho, Brasília, v. 17, n. 2, p. 137-139, jun. 2017. Disponível em: <http:// pepsic.bvsalud.org/pdf/rpot/v17n2/v17n2a09.pdf>. Acesso em: 23 jul. 2018. http://dx.doi.org/10.17652/ $\operatorname{rpot} / 2017.2 .12685$

GONDIM, S. M. G.; SIQUEIRA, M. M. M. Emoções e afetos no trabalho. In: ZANELLI, J. C.; BORGESANDRADE, J. E.; BASTOS, A. V. B (Org.). Psicologia, organizações e trabalho no Brasil. 2. ed. Porto Alegre: Artmed, 2014. p. 285-315.

GOSDAL, T. C. et al. Assédio moral organizacional: esclarecimentos conceituais e repercussões. In: GOSDAL, T. C.; SOBOLL, L. A. (Org.). Assédio moral interpessoal e organizacional: um enfoque interdisciplinar. São Paulo: LTr, 2009. p. 33-41.

GOULART, J. P. M.; GOULART JÚNIOR, E. Conceito e reflexões sobre o assédio moral no âmbito das relações de trabalho. In: CONGRESSO DE PSICOLOGIA ORGANIZACIONAL E DO TRABALHO DO CENTRO-OESTE PAULISTA, 2., 2017, Bauru. Anais... Bauru: Unesp, 2017. p. 305-313.

HELOANI, R. Assédio moral: um ensaio sobre a expropriação da dignidade no trabalho. RAE-eletrônica, São Paulo, v. 3, n. 1, p. 1-8, jan./jun. 2004. Disponível em: $\quad<$ http://www.scielo.br/pdf/raeel/v3n1/v3n1a12>. Acesso em: 23 jul. 2018.

HIRIGOYEN, M. F. Assédio moral: a violência perversa no cotidiano. 15. ed. Rio de Janeiro: Bertrand Brasil, 2014.

HUSSEIN, L. G. et al. Os assédios moral e sexual, a saúde do trabalhador e o papel do psicólogo organizacional e do trabalho. OMNIA Saúde, Adamantina, v. 12, p. 13-34, 2015.

JARDIM, S. Depressão e trabalho: ruptura de laço social. Revista Brasileira de Saúde Ocupacional, São Paulo, v. 36, n. 123, p. 84-92, jun. 2011. Disponível em: <http:// 
www.scielo.br/pdf/rbso/v36n123/a08v36n123.pdf $>$. Acesso em: 23 jul. 2018. http://dx.doi.org/10.1590/ S0303-76572011000100008

KUBO, S. H.; GOUVÊA, M. A. Análise de fatores associados ao significado do trabalho. Revista de Administração, São Paulo, v. 47, n. 4, p. 540-554, dez. 2012. Disponível em: <http://www.scielo.br/pdf/rausp/ v47n4/a03v47n4.pdf>. Acesso em: 23 jul. 2018.

LIMONGI-FRANÇA, A. C. Psicologia do trabalho: psicossomática, valores e práticas organizacionais. São Paulo: Saraiva, 2008.

MACÊDO, K. B. et al. Valores individuais e organizacionais: estudo com dirigentes de organizações pública, privada e cooperativa em Goiás. Cadernos de Psicologia Social do Trabalho, São Paulo, v. 8, p. 29-42, dez. 2005. Disponível em: <http://www.revistas.usp.br/ cpst/article/view/25873>. Acesso em: 23 jul. 2018.

MAGALDI, S.; SALIBI NETO, J. Gestão do amanhã: tudo o que você precisa saber sobre gestão, inovação e liderança para vencer na $4^{\mathrm{a}}$ revolução industrial. São Paulo: Gente, 2018.

MARTINS, L. M., Da concepção homem à concepção de psiquismo. In: A formação social da personalidade do professor. um enfoque vigotskiano. São Paulo: Autores Associados, 2007. p. 37-84.

MARTINS, L. M.; RABATINI, V. G. A concepção de cultura em Vigotski: contribuições para a educação escolar. Revista Psicologia Politica, São Paulo, v. 11, n. 22, p. 345-358, dez. 2011. Disponível em: <http://pepsic. bvsalud.org/pdf/rpp/v11n22/v11n22a11.pdf>. Acesso em: 23 jul. 2018.

MORIN, E. M. Os sentidos do trabalho. Revista de Administração de Empresas, São Paulo, v. 41, n. 3, p. 8-19, jul./set. 2001. Disponível em: <http://www.scielo. br/pdf/rae/v41n3/v41n3a02.pdf $>$. Acesso em: 23 jul. 2018.

NUNES, T. S. Assédio moral no trabalho: o contexto dos servidores da Universidade Federal de Santa Catarina. 2011. Dissertação (Mestrado em Administração) Universidade Federal de Santa Catarina, Florianópolis.

NUNES, T. S.; TOLFO, S. R. A dinâmica e os fatores organizacionais propiciadores à ocorrência do assédio moral no trabalho. Revista de Gestão e Secretariado, São Paulo, v. 4, n. 2, p. 90-113, 2013. Disponível em: <https:// www.revistagesec.org.br/secretariado/article/view/161>. Acesso em: 4 set. 2018. http://dx.doi.org/10.7769/gesec. v4i2.161

OLIVIER, M.; PEREZ, C. S.; BEHR, S. C. F. Trabalhadores afastados por transtornos mentais e de comportamento: o retorno ao ambiente de trabalho e suas consequências na vida laboral e pessoal de alguns bancários. Revista de Administração Contemporânea, Curitiba, v. 15, n. 6, p. 993-1015, dez. 2011. Disponível em: $\quad<\mathrm{http}: / /$ www.scielo.br/pdf/rac/v15n6/03.pdf $>$. Acesso em: 23 jul. 2018. http://dx.doi.org/10.1590/ S1415-65552011000600003

OMS - ORGANIZAÇÃO MUNDIAL DA SAÚDE. Classificação de transtornos mentais e de comportamento da CID-10: descrições clínicas e diretrizes diagnósticas. Porto Alegre: Artes Médicas, 2008.

OMS - ORGANIZACIÓN MUNDIAL DE LA SALUD. Sensibilizando sobre el coso psicológico en el trabajo: orientación para los profesionales de la salud, tomadores de decisiones, gerentes, directores de recursos humanos, comunidad jurídica, sindicatos y trabajador. Genebra, 2004. (Serie protección de la Salud de los Trabajadores, 4). Disponível em: <http://www.who.int/occupational health/publications/en/pwh4sp.pdf>. Acesso em: 4 set. 2018 .

PAI, D. D. et al. Violência física e psicológica perpetrada não trabalho em saúde. Texto e Contexto: Enfermagem, Florianópolis, v. 27, n. 1, mar. 2018. Disponível em: $<$ http://www.scielo.br/pdf/tce/v27n1/0104-0707-tce-2701-e2420016.pdf > . Acesso em: 4 set. 2018. http://dx.doi. org/10.1590/0104-07072018002420016

PENTEADO, C. P. M. et al. Liderança e assédio moral: a administração perversa do sentido do trabalho. Psicologia para América Latina, São Paulo, n. 21, p. 71-82, 2011. Disponível em $<$ http://pepsic.bvsalud.org/pdf/psilat/n21/ a06.pdf>. Acesso em: 23 jul. 2018.

RISSI, V. et al. Intervenções psicológicas diante do assédio moral no trabalho. Temas em Psicologia, Ribeirão Preto, v. 24, n. 1, p. 339-352, mar. 2016. Disponível em: <http://pepsic.bvsalud.org/pdf/tp/v24n1/v24n1a18. pdf $>$. Acesso em: 5 set. 2018. http://dx.doi.org/10.9788/ TP2016.1-23

SANTOS, M. A. F.; SIQUEIRA, V. S. S.; MENDES, A. M. Tentativas de suicídio de bancários no contexto das reestruturações produtivas. Revista de Administração Contemporânea, Curitiba, v. 14, n. 5, p. 925-938, set./ out. 2010. Disponível em: <http://www.redalyc.org/ articulo.oa? $\mathrm{id}=84015097010>$. Acesso em: 23 jul. 2018.

SELIGMANN-SILVA, E. Psicopatologia da violência e suas expressões clínicas. In: . (Org.). Trabalho e desgaste mental: o direito de ser dono de si mesmo. São Paulo: Cortez, 2011. p. 492-549.

SILVA, G. G. J. et al. Considerações sobre o transtorno depressivo no trabalho.Revista Brasileira de Saúde Ocupaciona, São Paulo, v. 34, n. 119, p. 79-87, jun. 
2009. Disponível em: <http://www.scielo.br/pdf/rbso/ v34n119/09v34n119.pdf>. Acesso em: 23 jul. 2018. http://dx.doi.org/10.1590/S0303-76572009000100009

SILVA, L. P.; CASTRO, M. A. R.; DOS-SANTOS, M. G. Influência da cultura organizacional mediada pelo assédio moral na satisfação no trabalho. Revista de Administração Contemporânea, Curitiba, v. 22, n. 2, p. 249-270, abr. 2018. Disponível em: <http://www.scielo. $\mathrm{br} / \mathrm{pdf} / \mathrm{rac} / \mathrm{v} 22 \mathrm{n} 2 / 1982-7849-\mathrm{rac}-22-02-0249 . \mathrm{pdf}>$. Acesso em: 4 set. 2018. http://dx.doi.org/10.1590/19827849rac2018170176

SIQUEIRA, M. M. M.; GOMIDE JÚNIOR, S. Suporte no trabalho. In: SIQUEIRA, M. M. M. (Org.). Medidas do comportamento organizacional: ferramentas de diagnóstico e de gestão. Porto Alegre: Artmed, 2008. p. 283-294.

SIQUEIRA, M. M. M.; GOMIDE JÚNIOR, S. Vínculos do indivíduo com o trabalho e com a organização. In: ZANELLI, J. C.; BORGES-ANDRADE, J. E.; BASTOS, A. V. B. (Org.). Psicologia, organizações e trabalho no Brasil. 2. ed. Porto Alegre: Artmed, 2014. p. 317-348.
SOARES, A.; OLIVEIRA, J. A. Assédio moral no trabalho. Revista Brasileira de Terapia Ocupacional, São Paulo, v. 37, n. 126, p. 195-202, dez. 2012. Disponível em: $<$ http://www.scielo.br/pdf/rbso/v37n126/a02v37n126. pdf $>$. Acesso em: 4 set. 2018. http://dx.doi.org/10.1590/ S0303-76572012000200002

SOBOLL, L. A. P. Assédio moral/organizacional: uma análise da organização do trabalho. São Paulo: Casa do Psicólogo, 2008.

SOBOLL, L. A. P. Intervenções em assédio moral e organizacional. São Paulo: LTr, 2017.

SPECTOR, P. E. Psicologia nas organizações. 4. ed. São Paulo: Saraiva, 2012.

XAVIER, A. C. H. et al. Assédio moral no trabalho no setor saúde no Rio de Janeiro: algumas características. Revista Brasileira de Saúde Ocupacional, São Paulo, v. 33 , n. 117 , p. 15-22, jun. 2008. Disponível em: $<$ http://www.scielo.br/pdf/rbso/v33n117/a03v33n117. pdf $>$. Acesso em: 4 set. 2018. 